\title{
Transformation of dissolved organic matter in a constructed wetland: A molecular-level composition analysis using pyrolysis-gas chromatography mass spectrometry
}

\author{
Jongkwan Park ${ }^{1}$, Mijin Choi ${ }^{1}$, Jaeweon Cho' ${ }^{1}$,yongmi Chon ${ }^{+}$ \\ ${ }^{1}$ School of Urban and Environmental Engineering, Ulsan National Institute of Science and Technology (UNIST), Ulsan 44919, Republic of Korea \\ ${ }^{2}$ Chemical Safety Division, Department of Agro-Food Safety \& Crop Protection, National Institute of Agricultural Sciences, Wanju-gun 55365, \\ Republic of Korea
}

\begin{abstract}
This study investigated the transformation of dissolved organic matter (DOM) in a free-water surface flow constructed wetland. Pyrolysis gas chromatography-mass spectrometry (Py-GC/MS) coupled with preparative high-performance liquid chromatography (prep-HPLC) was used to analyze the compositions of biopolymers (polysaccharides, amino sugars, proteins, polyhydroxy aromatics, lipids and lignin) in DOM according to the molecular size at three sampling points of the water flow: inflow, midflow, and outflow. The prep-HPLC results verified the decomposition of DOM through the decrease in the number of peaks from three to one in the chromatograms of the sampling points. The Py-GC/MS results for the degradable peaks indicated that biopolymers relating to polysaccharides and proteins gradually biodegraded with the water flow. On the other hand, the recalcitrant organic fraction (the remaining peak) in the outflow showed a relatively high concentration of aromatic compounds. Therefore, the ecological processes in the constructed wetland caused DOM to become more aromatic and homogeneous. This indicated that the constructed wetland can be an effective buffer area for releasing biochemically stable DOM, which has less influence on biological water quality indicators, e.g., biochemical oxygen demand, into an aquatic ecosystem.
\end{abstract}

Keywords: Biopolymer, Dissolved organic matter, Preparative high-performance liquid chromatography, Pyrolysis gas chromatography-mass spectrometry, Surface flow constructed wetland

\section{Introduction}

Organic matter removal in a constructed wetland is associated with biological, chemical, and physical mechanisms, such as settling, adsorption, microbial activity, and photo-degradation [1-3]. Generally, particulate organic matter is removed by sedimentation and filtration, whereas the amount of dissolved organic matter (DOM) can increase or decrease according to the design of the constructed wetland. This is because DOM can be assimilated or produced by biological processes in such wetlands. DOM influences the chemical interactions and biological availability of trace elements and synthetic organic compounds. Therefore, not only the removal rate but also the characterization of DOM is important for considering the design of a constructed wetland to improve water treatment processes.

However, few studies on characterizing DOM in a constructed wetland exist. Barber et al. [4] investigated the transition of DOM through a free-water surface constructed wetland in San Jacinto, California. These authors analyzed various characteristics of DOM, such as DOM fractions, with a hydrophobic sorbent, Fourier transform infrared spectroscopy, and C-13/H nuclear magnetic resonance. The dissolved organic carbon (DOC) concentration increased because of planted plants and the proportion of hydrophobic organic compounds decreased owing to algal blooms that released hydrophilic compounds as autochthonous organic matter in the constructed wetland [4]. According to Quanrud et al. [5], DOM in the influent of a sub-surface constructed wetland changed from hydrophilic to hydrophobic and
This is an Open Access article distributed under the terms of the Creative Commons Attribution Non-Commercial License (http://creativecommons.org/licenses/by-nc/3.0/) which permits unrestricted non-commercial use, distribution, and reproduction in any medium, provided the original work is properly cited.
Received January 23, 2018 Accepted April 2, 2018

${ }^{\dagger}$ Corresponding author

Email: gracechkm@gmail.com

Tel: +82-63-238-3252 Fax: +82-63-238-3837

Copyright (C) 2018 Korean Society of Environmental Engineers 
from easily biodegradable to non-biodegradable in the effluent.

One of the major difficulties when conducting experiments to characterize DOM is its heterogeneity. Fractionation is widely used to reduce DOM heterogeneity (e.g., hydrophobic sorbent (XAD and C-18 resins), ultrafiltration (UF), and size exclusion chromatography). The XAD fractionation method has been applied to characterize DOM in a pilot-scale horizontal sub-surface constructed wetland. It was found that polyphenolic compounds in water are increased by DOM from roots and leaves, and hydrophilic organic matter is more biodegradable than hydrophobic organic matter [6]. UF fractionation was used to study DOM in a vertical sub-surface constructed system, and it was found that large organic matter $(>10 \mathrm{kDa})$ was more biodegradable, and hydrophobic organics rather than hydrophilic organics were preferentially removed, which were fractionated by XAD resin [7]. However, XAD resin and UF have limitations. XAD resin is effective at absorbing hydrophobic organics but poor at collecting hydrophilic organics. UF is not practical for fractionating DOM with a molecular weight lower than $1 \mathrm{kDa}$ because of the limitation of the molecular weight cutoff of UF.

To overcome these limitations, preparative high-performance liquid chromatography (prep-HPLC) was designed for DOM fractionation [8]. Prep-HPLC allows DOM to be fractionated according to the molecular size (lower than 1,000 Da) or hydrophobicity $[9,10]$. As the system can be operated automatically, it can reduce the time and several steps during experiments. Recently, the fractionation method has been used for DOM characterization because it allows further analysis with large fractionated volumes $[11,12]$.

Pyrolysis gas chromatography-mass spectrometry (Py-GC/MS) is a tool for defining organic molecular structure. Because of its low selectivity, this system has been used to investigate the structure of organic matter in many environmental samples [13-15]. Schulten and Gleixner [13] classified pyrolyzed fragments into ten groups: carbohydrates, phenols and lignin monomers, lignin dimers, lipids, alkylaromatics, aromatic nitrogen compounds, sterols, peptides, suberin, and loosely bound fatty acids. Based on the results, these authors inferred the origins of organic matter. This method has also been used to estimate biodegradability or humification rate [12, 16, 17]. Therefore, the combination of prep-HPLC and Py-GC/MS is a powerful tool for reducing the heterogeneity of DOM and increasing the profiling accuracy with low selectivity.

The purpose of this study was to investigate the transformation of DOM in a free-water surface flow constructed wetland for secondary treatment of wastewater treatment plant (WWTP) effluent. Investigating the fate of DOM is necessary for predicting its removal efficiency or biodegradability, which are useful factors for managing a constructed wetland. Therefore, the change in the molecular size distribution of DOM was monitored, and DOM was fractionated according to its size with the prep-HPLC system. Subsequently, the biopolymer compositions of each sampling site were analyzed to estimate the biodegradability of DOM. The experimental results provided significant information for understanding the transformation of DOM.

\section{Materials and Methods}

\subsection{Sampling}

Sampling was conducted on July 27, 2012 at a free-water surface constructed wetland in Korea $\left(34^{\circ} 89^{\prime} \mathrm{N}, 127^{\circ} 13^{\prime} \mathrm{E}\right)$. This constructed wetland was installed as a secondary treatment system for the effluent from a WWTP. The constructed wetland consisted of a forebay, planted wetlands, and a micropool (Fig. 1). The planted wetlands were divided into three parts with ponds containing the following species: (1) Oenanthe javanica and Nymphaea tetragona, (2) Phragmites australis and Typha orientalis, and (3) T. orientalis and Zizania latifolia. The entire wetland covered an area of 13,655 $\mathrm{m}^{2}$, the daily treatment capacity was $300 \mathrm{~m}^{3} / \mathrm{d}$, and the hydraulic retention time (HRT) was 7 d. Three sampling points were selected based on the water flow, namely inflow, midflow, and outflow. Each sampling point was selected to characterize the organic matter according to the water flow in the constructed wetland. The inflow point contained effluent organic matter (EfOM) and algal organic matter because the water sample included organic matter from the WWTP and forebay, where algal blooms had occurred on the sampling date. The midflow point was selected based on where the characteristics of the organic matter started to change due to the ecological treatment processes. Finally, the outflow point was selected to identify the transformed organic matter. Field measurements were conducted in terms of $\mathrm{pH}$, temperature, and conductivity. Samples were filtrated with 0.45 micro-filters (mixed cellulose acetate, Advantech, Japan) and were stored at $4^{\circ} \mathrm{C}$ for further analysis.

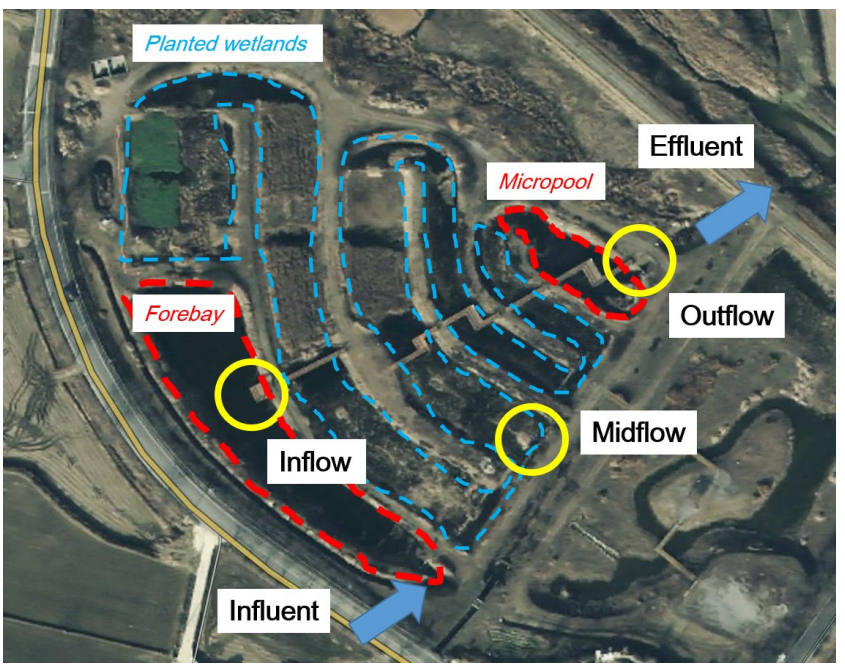

Fig. 1. Water flow directions and sampling points of the constructed wetland.

\subsection{Sample Analysis}

Three repetitions were taken at each sampling point during a single sampling period. The DOC and total nitrogen (TN) concentrations of the samples were measured with a total organic carbon analyzer (TOC-V CPH, Shimadzu, Japan) equipped with a TN 
analyzer (TNM-1, Shimadzu, Japan). An ultraviolet (UV)-visible spectrometer (UV-1601, Shimadzu, Japan) was used to measure the UV absorbance of the samples at $254 \mathrm{~nm}\left(\mathrm{UVA}_{254}\right)$. The specific UV absorbance (SUVA) value was calculated from the $\mathrm{UVA}_{254}$ and DOC values. The ion concentration was measured with ion chromatography (ICS-90, Dionex, CA, USA). An AS14 column $(250 \times 4 \mathrm{~mm}$, Dionex, CA, USA) was used to measure the nitrite and nitrate concentrations. The molecular weight distribution of the fractionated samples was measured by using high-performance size-exclusion chromatography (HPSEC) equipped with an SEC column (Protein Pak 125, Waters, MA, USA). The eluent consisted of $2.4 \mathrm{mM}$ sodium phosphate, 1.6 $\mathrm{mM}$ disodium hydrogen phosphate, and $96.0 \mathrm{mM}$ sodium chloride. The UVA detector (SPD-10AVP, Shimadzu, Japan) was connected to the column. The flow rate of the eluent was 0.7 $\mathrm{mL} / \mathrm{min}$, and the injection volume was $200 \mu \mathrm{L}$. Polystyrene sulfonates $(210 ; 1.8,4.6,8$, and $18 \mathrm{kDa})$ were used as standards for determining the molecular weight calibration curve.

\subsection{Prep-HPLC}

A rotary evaporator (N-1200A, EYELA, Japan) was used to concentrate the samples. The DOC concentration increased 20 to 40 folds depending on the amount of sample available. Since some organic matter is lost in the evaporation process, the final DOC concentrations of the samples were $36.4 \mathrm{mg} \mathrm{C} / \mathrm{L}$ for the inflow (30-fold increase, 39\% organic matter loss), $91.6 \mathrm{mg} \mathrm{C} / \mathrm{L}$ for the midflow (40-fold increase, $34 \%$ organic matter loss), and $49.8 \mathrm{mg} \mathrm{C} / \mathrm{L}$ for the outflow (20-fold increase, 38\% organic matter loss). A prep-HPLC system (JAI-LC-9201, JAI, Japan) was used with a GS-310 column $(500 \times 20 \mathrm{~mm}$, JAI, Japan $)$ and UV detector 3702 (JAI, Japan). The wavelength of the UV detector was 254 $\mathrm{nm}$, and the operating flow rate of the eluent was $5 \mathrm{~mL} / \mathrm{min}$. Deionized water was used as an eluent. A gas-tight syringe was used to inject $5 \mathrm{~mL}$ samples.

\section{4. $P y-G C / M S$}

A Curie-point pyrolyzer (JCI-22, JAI, Japan) was used for organic pyrolysis. Approximately $0.1 \mathrm{mg}$ of the sample was prepared in a ferromagnetic foil (Pyrofoil F590, JAI, Japan). The pyrolysis temperature was $590^{\circ} \mathrm{C}$, and the volatilized compounds were injected into an Agilent 7890A GC/MS (5975C, Agilent, CA, USA). A DB-5MS (30 m, $0.25 \mathrm{~mm}$, i.d., film thickness $0.50 \mu \mathrm{m}$ ) was used for separation with helium as the carrier gas. The initial oven temperature was maintained at $40^{\circ} \mathrm{C}$, and the final temperature was $300^{\circ} \mathrm{C}$. The rate of the temperature rise was $7^{\circ} \mathrm{C} / \mathrm{min}$, and the holding time at the final temperature was 10 min. The ion source was at a temperature of $210^{\circ} \mathrm{C}$. The compounds were ionized at $70 \mathrm{eV}$ and mass analyzed over a range of 30-500 amu. The pyrolyzed fragments of the three samples were categorized into six groups based on Bruchet et al.'s (1990) work: polysaccharides, amino sugars, proteins, polyhydroxy aromatic (PHA) compounds, lignin, and lipids.

\section{Results and Discussion}

\subsection{Changing of Water and Biomolecular Characteristics through the Constructed Wetland}

Table 1 summarizes the water characteristics. The $\mathrm{pH}$ value at the inflow was relatively high (8.3) because of algal blooms in the forebay. The TN concentration decreased with the water flow. From the inflow to the outflow point, TN was reduced from 1.7 to $0.6 \mathrm{mg} \mathrm{N} / \mathrm{L}$. This was ascribed to the nitrification, denitrification, and plant uptake processes in the constructed wetland [18-20]. The nitrite concentration gradually decreased as the water flowed from the inflow to the outflow point, but the nitrate concentration increased at the midflow point and then decreased at the outflow point. These results can also be explained by nitrification and plant uptake. Nitrite is oxidized to nitrate during the nitrification process; this causes the nitrite to decrease and nitrate to increase. The decrease after the increase in the nitrate concentration can be explained by plant uptake. Lin et al. [21] reported a high nitrate removal rate $\left(0.63-1.26 \mathrm{~g} \mathrm{NO}_{3}-\mathrm{N} / \mathrm{m}^{2} / \mathrm{d}\right)$ via plant uptake in wetlands planted with five macrophytes (Phragmites australis, Commelina communis, Pennisetum purpureum, Ipomoea aquatica, and Pistia stratioes). In this study, the densely planted area (with Phragmites australis, Typha orientalis, and Zizania latifolia) started from the midflow sampling point and ended at the outflow sampling point. Therefore, the nitrate concentration may have been influenced by existing plants.

Table 1. Water Characteristics of Sampling Points $(n=3)$

\begin{tabular}{|c|c|c|c|}
\hline & Inflow & Midflow & Outflow \\
\hline $\mathrm{pH}$ & 8.3 & 7.5 & 7.2 \\
\hline Temperature $\left({ }^{\circ} \mathrm{C}\right)$ & 25 & 27 & 27 \\
\hline Conductivity $(\mu \mathrm{S} / \mathrm{cm})$ & 162 & 161 & 158 \\
\hline DOC (mg C/L) & $2.0( \pm 0.3)$ & $3.5( \pm 0.5)$ & $4.0( \pm 0.2)$ \\
\hline UV $254\left(\mathrm{~cm}^{-1}\right)$ & $0.0543( \pm 0.0003)$ & $0.0810( \pm 0.0005)$ & $0.0896( \pm 0.0002)$ \\
\hline SUVA $\left(\mathrm{L} \mathrm{m}^{-1} \mathrm{mg}^{-1}\right)$ & $2.67( \pm 0.46)$ & $2.31( \pm 0.32)$ & $2.27( \pm 0.10)$ \\
\hline Total nitrogen (mg N/L) & $1.7( \pm 0.1)$ & $0.8( \pm 0.0)$ & $0.6( \pm 0.1)$ \\
\hline Nitrite (mg N/L) & $0.27( \pm 0.3)$ & $0.29( \pm 0.2)$ & $0.14( \pm 0.2)$ \\
\hline Nitrate (mg N/L) & $0.35( \pm 0.2)$ & $0.48( \pm 0.4)$ & $0.18( \pm 0.3)$ \\
\hline
\end{tabular}


However, the DOC concentration increased as the water flowed from the inflow point to the outflow point. This finding can be explained by the activity of the vegetation in the wetland. The life cycles of plants end when they decompose in the water, after which their debris generates organic matter. The SUVA is an indicator for estimating the hydrophobicity of DOM in a water sample. A high value indicates that DOM consists of hydrophobic compounds such as PHAs. An SUVA value of between 2 and 4 indicates that DOM consists of a mixture of hydrophobic and hydrophilic organic matter [22]. However, the SUVA values of all samples showed no distinguishable differences regarding the hydrophobicity (inflow: 2.67, midflow: 2.31, and outflow: 2.27).

Based on the above results, the presence of plants and microorganisms in a constructed wetland affected the transformation of organic matter. Py-GC/MS analysis was conducted to investigate the changes in the biomolecular composition of the organic matter in each sample (Fig. 2). The most remarkable trend in these biomolecular compositions was that lipids and proteins decreased as water flowed from the inflow, through the midflow, to the outflow point (lipids: 26,19 , and $7 \%$, respectively; proteins: 40,37 , and $24 \%$, respectively); lipids and proteins are biomolecules related to the debris of microorganisms as these compounds make up cell structures. These relatively high concentrations of lipids (26\%) and proteins $(40 \%)$ at the inflow point can be ascribed to the EfOM and algal organic matter contained in the wastewater effluent. However, these compounds decomposed as they passed through the constructed wetland, and their concentrations were reduced. This decrease therefore indicates that organic matter from microbial sources was removed.

On the other hand, the concentration percent of PHAs increased with the water flow, which could have been caused by the humification of organic matter in a constructed wetland [23]. Humification is a process forming macromolecular humic substances by chemical aggregation with small molecules [24] and the decomposition of biodegradable molecules [25]. PHA and lignin are biomolecules originating from plants. Because lignin has benzene rings with methoxyl groups, the functional group breaks away easily from the lignin structure, and the remaining aromatic compounds can be classified as a PHA group. Therefore, the increase in the concentration percent of PHAs indicates that organic matter originating from plants, containing lignin molecules, was continuously added as the water passed through the constructed wetland. This is connected to the results in Table 1, indicating that the DOC concentration increased with the water flow.

Another possible reason for the increase in PHA is polymerization. According to Steinberg and Münster [26], lignin monomers are important due to their accelerated polymerization in the presence of transition metals, clays, amino acids, and sugars. Harvey and Henry [27] proposed an alternative polymerization model where free radicals in unsaturated lipids form cross-links. These two models can be used to explain the decrease in lipids and lignin and increase in PHA in this result (Fig. 2).

The concentration percent of amino sugars and polysaccharides could have been expected to increase continuously

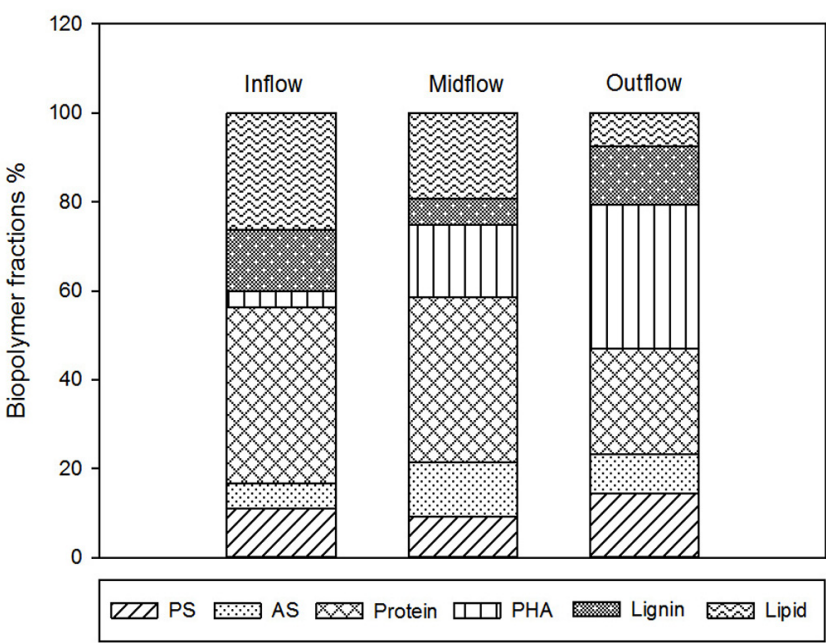

Fig. 2. Fraction of biopolymers for sampling points. PS = polysaccharides; AS = amino sugars; PHA $=$ polyhydroxy aromatics.

with water flow as they can originate from microbial extracellular polymeric substances (EPS), decomposing plants, or microbial residues. However, the compositions did not increase in this study. This seems to have been the case because microorganisms in the constructed wetland used these compounds, which are highly biodegradable, as sources of nutrient.

\subsection{Fractionation of DOM Using Preparative HPSEC}

A prep-HPLC system was used to fractionate the molecular samples according to size. Fig. 3 shows the chromatograms from the prep-HPLC system. The inflow and midflow samples showed three peaks in the UV response, but the outflow sample had only one peak. The change in the detected number of peaks indicated that the molecular characteristics of the WWTP effluent were transformed in the constructed wetland. The decomposition of peaks \#1, \#2, and \#3 of the inflow sample was observed by comparing the chromatograms of the samples (Fig. 3). The molecular weights of peaks \#1 and \#2 of the inflow sample were 2,500 and 1,700 Da, respectively, but they were reduced to 1,800 and $1,500 \mathrm{Da}$, respectively, in the midflow sample. Finally, peaks \#1 and \#3 disappeared from the outflow sample; only one peak, which was assumed to be the degraded form of peak \#2, remained.

Lee et al. [12] studied the same type of constructed wetland (i.e., free-water surface flow, treating effluent of a WWTP). These authors reported that there were also three peaks in the chromatogram of prep-HPLC from the effluent of the constructed wetland. However, in this study, there was only one peak in the effluent of the constructed wetland. This difference was derived from the differences in the HRT. Lee et al.'s results showed the chromatogram of DOM in the effluent of the constructed wetland having an HRT of $6 \mathrm{~h}$. In this study, however, the HRT was $7 \mathrm{~d}$. Since ecological processes are the major treatment mechanism in a constructed wetland, a longer HRT should enhance the changes in the DOM characteristics. A large number of peaks meant that various sizes of organic molecules existed in the sample, 

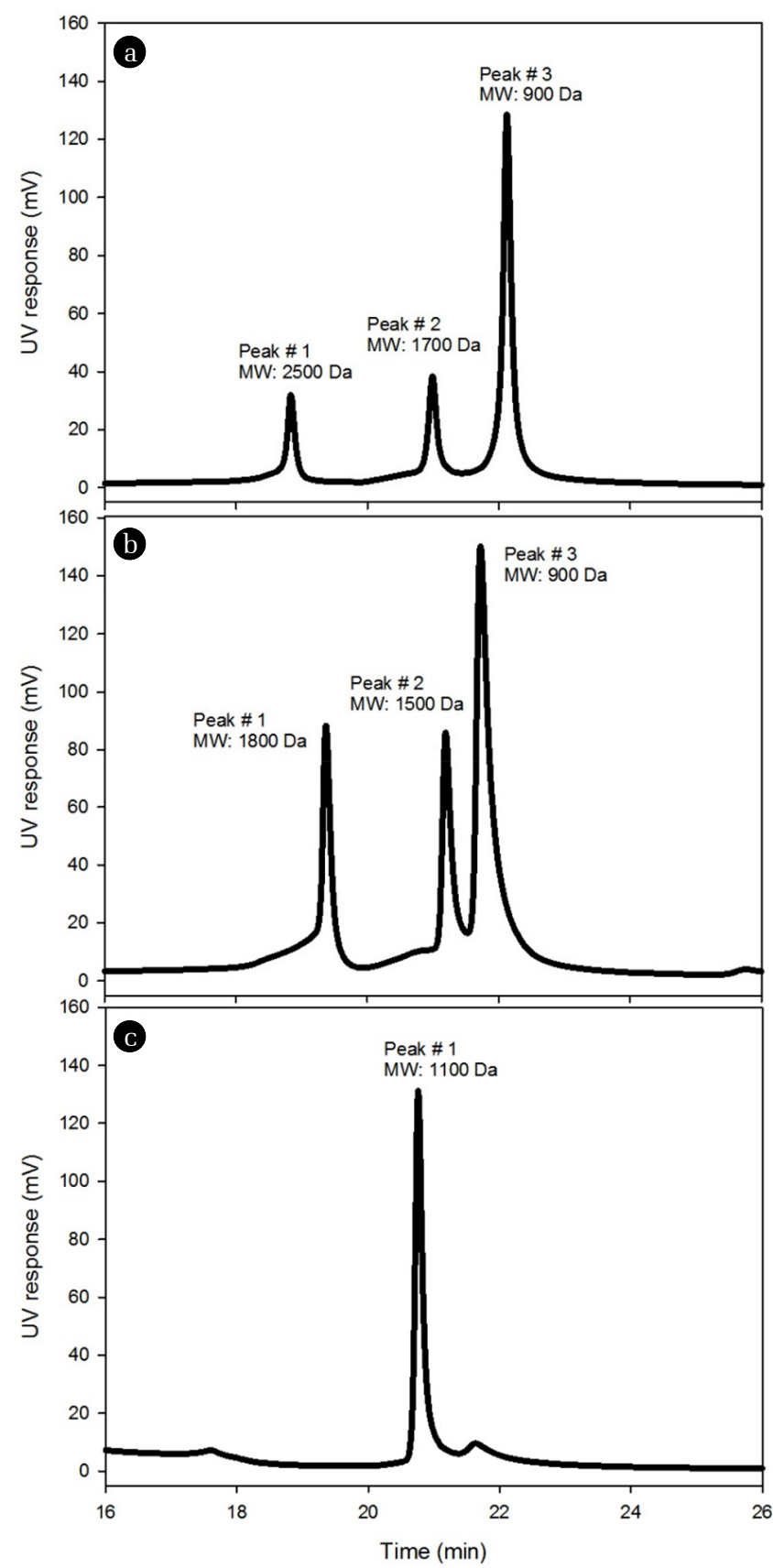

Fig. 3. Chromatograms of DOMs included in the each sampling points from preparative HPLC. (a) inflow, (b) midflow, and (c) outflow points. The molecular weight was calculated by the analytical HPLC system.

and thus fewer peaks implied that the heterogeneity of the organic matter was reduced. In other words, the number of peaks was reduced from three to one because of the enhanced ecological processes associated with a relatively long HRT. These results therefore illustrated the biodegradation of organic matter in the constructed wetland. EfOM and algal organic matter at the inflow started to decompose slowly once they flowed through the con- structed wetland, and the outflow sample indicated totally decomposed organic matter.

\subsection{Biomolecular Composition of DOM Fractionations}

The biomolecular composition of each peak was analyzed by Py-GC/MS after fractionation of DOM using prep-HPLC. In the inflow sample, the first peak showed a relatively high concentration percent (42.6\%) of polysaccharides (Fig. 4), which decreased with the decreasing molecular weight (increasing retention time in the prep-HPLC column; peak \#1: 42.6\%, peak \#2: $26.0 \%$, and peak \#3: $19.9 \%$ ). It could be expected that peak \#1 of the inflow sample would consisted mainly of EPS from EfOM and algal organic matter because polysaccharides are dominant compounds in EPS and have a high molecular weight. Peak \#2 had a similar concentration percent of lipids than peak \#1 (31.2 and 30.2\%, respectively) but fewer polysaccharides (peak \#1: $42.6 \%$ and peak \#2: 26.0\%). Peak \#2 had the highest concentration percent of both lignin (5.9\%) and amino sugars (11.8\%), with the lowest concentration percent of proteins $(10.0 \%)$ among the peaks in the inflow sample. Since proteins have a high biodegradability, peak \#2 could be expected to be more recalcitrant than the other peaks (Fig. 4). In peak \#3, proteins were the dominant biopolymers (35.6\%). Proteins are classified as biopolymers originating from microorganisms because they are the building blocks of cells. Therefore, peak \#3 could be expected to represent the debris of microorganisms because of the low molecular weight and high protein concentration percent. Overall, therefore, the inflow sample contained a relatively high concentration percent of lipids, proteins, and polysaccharides.

The three peaks in the midflow sample showed a similar pattern to that of the inflow sample. Peak \#1 had the highest concentration percent of polysaccharides (37.6\%). Peak \#2 had the lowest protein concentration percent (2.2\%), whereas peak \#3 had the highest (38.5\%). Every peak contained lignin (peak \#1: 5.8\%, peak \#2: 4.6\%, and peak \#3: 4.7\%). This indicates that organic matter originating from plants was added to the water passing through the constructed wetland as lignin originates from plants.

The outflow sample had only one peak. The molecular weight and biopolymer factions of peak \#1 of the outflow sample differed from peak \#2 of the inflow and midflow samples (Fig. 3 and 4). Therefore, it cannot be considered the same organic matter fraction as that in the earlier flows. However, peak \#1 of the outflow sample appeared to be a decomposed form of peak \#2 of the earlier flows because its molecular weight was lower than that of the others (peak \#2 of the inflow sample: 1,700 Da; peak \#2 of the midflow sample: 1,500 Da; peak \#1 of the outflow sample: 1,100 Da). Kim et al. [28] also reported that the distribution of molecule weight moved from a high mass region to a low mass region based on water flow. In their paper, the reason for the decreasing molecular weight was biodegradability of the DOM. In addition, the biopolymer composition of peak \#1 was similar to that of peak \#2 of the inflow and midflow samples (Fig. 4).

Peaks \#1 and \#3 of the midflow sample disappeared by the 


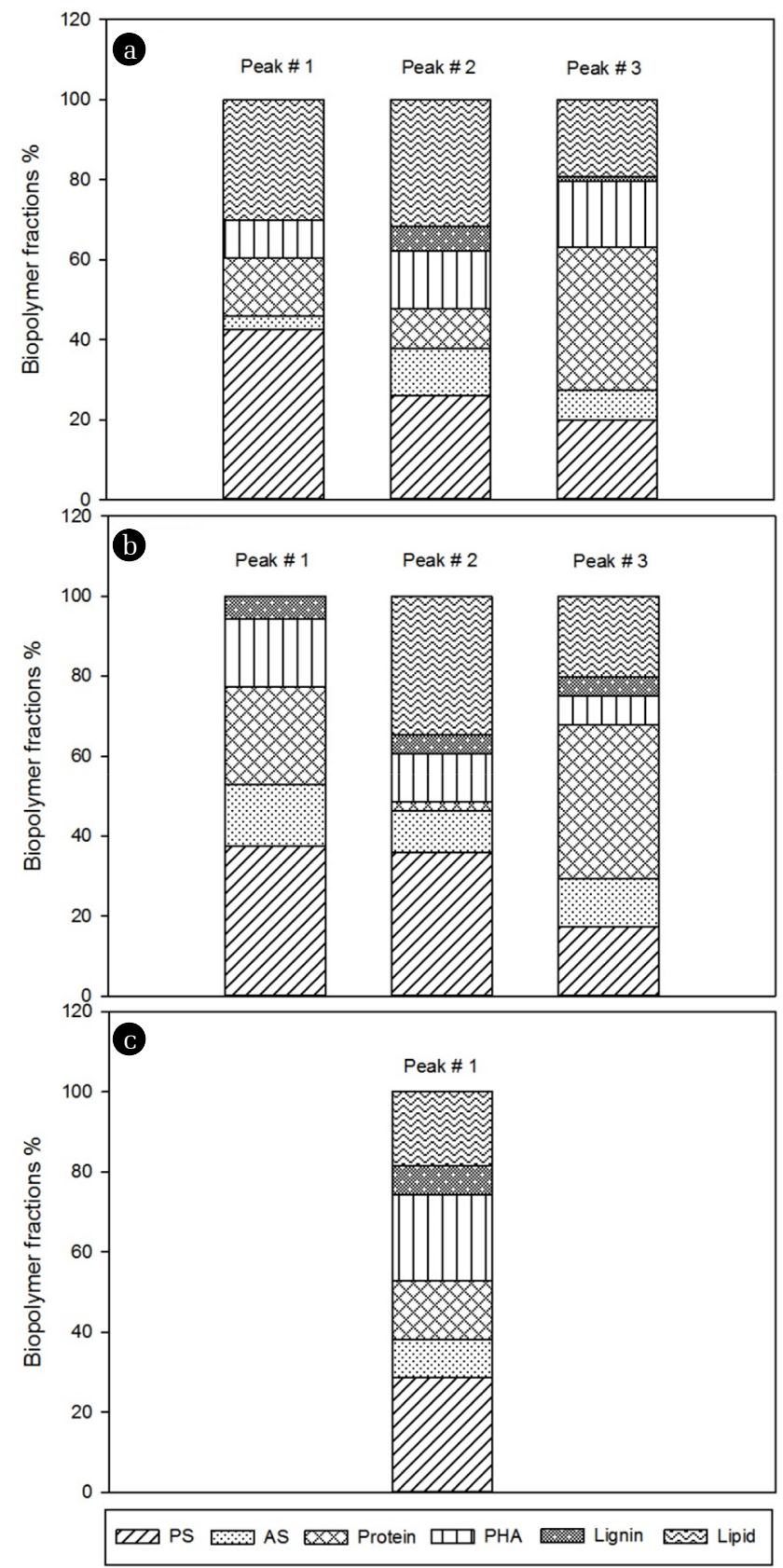

Fig. 4. Fractions of biopolymers for DOMs separated by prep-HPLC in each sampling points. (a) inflow, (b) midflow, and (c) outflow. $\mathrm{PS}=$ polysaccharides; $\mathrm{AS}=$ amino sugars; $\mathrm{PHA}=$ polyhydroxy aromatics.

time when the water reached the outflow point, indicating that the compounds represented by the peaks were highly biodegradable. Some earlier studies investigated the relationship between molecular weight and biodegradability. One showed the result that low molecular weight DOM is easily degraded by bacteria [29] but another study found the opposite results [30]. To avoid this controversial issue, the biodegradability of the DOM in peak \#1 and \#2 were estimated using the biopolymer composition. Saccharides and proteins are well-known to be sources of microbial growth [31]. In addition, protein and amino acids have been reported to be major nutrient sources for microorganisms because the nitrogen in these substances is an essential element for their growth. Thus, the protein and amino acids in peaks \#1 and \#3 can easily be degraded by various microorganisms [32]. Therefore, the high concentration percent of proteins and polysaccharides of peaks \#1 and \#3 of the midflow sample indicated that they were highly biodegradable, more than those of peak \#2.

\section{Conclusions}

This study investigated the changes in molecular characteristics of DOM passing through a constructed wetland. The free-water surface flow type did not exhibit an effective DOM removal performance, and the DOC concentration increased almost twofold from 2.0 to $4.0 \mathrm{mgC} / \mathrm{L}$ with the flow of water. An increase in DOM is inevitable in this type of constructed wetland because of the densely planted vegetation; the debris from their lifecycle causes an increase in the DOC concentration. This may be considered a drawback from a water quality management point of view. Nonetheless, the experimental results from Py-GC/MS coupled with prep-HPLC indicated that the free-water surface flow constructed wetland decreased the heterogeneity and increased the recalcitrant concentration percent of DOM. The molecular weight distribution was simplified when a chromatogram from the outflow sample was compared to those of earlier flows in the constructed wetland. In addition, the Py-GC/MS results showed that the biodegradable organic matter was removed as the water flowed. The concentration percent of polysaccharides and proteins in the fractionated DOM decreased, and the recalcitrant DOM fraction, which consisted of lignin and PHA, relatively increased. These results indicated that (1) the constructed wetland can be an effective buffer area for releasing biochemically stable DOM, which has less influence on biological water quality indicators like biochemical oxygen demand, into an aquatic ecosystem, and (2) the analytical method of Py-GC/MS coupled with prep-HPLC can be an effective and precise tool for characterizing organic matter.

\section{Acknowledgments}

This work was supported by the National Research Foundation of Korea (NRF) Grant funded by the Korean Government (MSIP) (No. NRF-2017K1A3A9A01013898 \& No. NRF-2015R1A5A70 37825).

\section{References}

1. Vymazal J. Removal of nutrients in various types of constructed wetlands. Sci. Total Environ. 2007;380:48-65.

2. Lee E, Shon HK, Cho J. Role of wetland organic matters 
as photosensitizer for degradation of micropollutants and metabolites. J. Hazard. Mater. 2014;276:1-9.

3. Matamoros V, Bayona JM. Elimination of pharmaceuticals and personal care products in subsurface flow constructed wetlands. Environ. Sci. Technol. 2006;40:5811-5816.

4. Barber LB, Leenheer JA, Noyes TI, Stiles EA. Nature and transformation of dissolved organic matter in treatment wetlands. Environ. Sci. Technol. 2001;35:4805-4816.

5. Quanrud DM, Karpiscak MM, Lansey KE, Arnold RG. Transformation of effluent organic matter during subsurface wetland treatment in the Sonoran Desert. Chemosphere 2004;54:777-788.

6. Wei L-L, Zhao Q-L, Xue S, Jia T, Tang F, You P-Y. Behavior and characteristics of DOM during a laboratory-scale horizontal subsurface flow wetland treatment: Effect of DOM derived from leaves and roots. Ecol. Eng. 2009;35:1405-1414.

7. Du X, Xu Z, Li J, Zheng L. Characterization and removal of dissolved organic matter in a vertical flow constructed wetland. Ecol. Eng. 2014;73:610-615.

8. Piccolo A, Conte P, Trivellone E, van Lagen B, Buurman P. Reduced heterogeneity of a lignite humic acid by preparative HPSEC following interaction with an organic acid. Characterization of size-separates by Pyr-GC-MS and 1H-NMR spectroscopy. Environ. Sci. Technol. 2002;36:76-84.

9. Park J, Chon K, Lee E, Cho J. Developing a large-volume preparative method using a handmade HPLC column to fractionate dissolved organic matter. Desalin. Water Treat. 2017; 67:97-104.

10. Bünger H, Kaufner L, Pison U. Quantitative analysis of hydrophobic pulmonary surfactant proteins by high-performance liquid chromatography with light-scattering detection. $J$. Chromatogr. A 2000;870:363-369.

11. Chon K, Chon K, Cho J. Characterization of size fractionated dissolved organic matter from river water and wastewater effluent using preparative high performance size exclusion chromatography. Org. Geochem. 2017;103:105-112.

12. Lee D, Cho J, Chon K, Lim B, Chakraborty S, Chon K. Role of a constructed wetland to humify effluent organic matter from a wastewater treatment plant. Desalin. Water Treat. 2014;52:5840-5847.

13. Schulten HR, Gleixner G. Analytical pyrolysis of humic substances and dissolved organic matter in aquatic systems: Structure and origin. Water Res. 1999;33:2489-2498.

14. Chefetz B, Tarchitzky J, Deshmukh AP, Hatcher PG, Chen Y. Structural characterization of soil organic matter and humic acids in particle-size fractions of an agricultural soil. Soil Sci. Soc. Am. J. 2002;66:129-141.

15. Kaal J, Wagner S, Jaffé R. Molecular properties of ultrafiltered dissolved organic matter and dissolved black carbon in headwater streams as determined by pyrolysis-GC/MS. J. Anal. Appl. Pyrolysis 2016;118:181-191.

16. Khabbaz F, Karlsson S, Albertsson AC. PY-GC/MS an effective technique to characterizing of degradation mechanism of poly (L-lactide) in the different environment. J. Appl. Polym. Sci. 2000;78:2369-2378.
17. Katsumi N, Yonebayashi K, Okazaki M, et al. Characterization of soil organic matter with different degrees of humification using evolved gas analysis-mass spectrometry. Talanta 2016;155:28-37.

18. Platzer C. Design recommendations for subsurface flow constructed wetlands for nitrification and denitrification. Water Sci. Technol. 1999;40:257-263.

19. Chon K, Chang J-S, Lee E, Lee J, Ryu J, Cho J. Abundance of denitrifying genes coding for nitrate (narG), nitrite (nirS), and nitrous oxide (nosZ) reductases in estuarine versus wastewater effluent-fed constructed wetlands. Ecol. Eng. 2011;37:64-69.

20. Koottatep T, Polprasert C. Role of plant uptake on nitrogen removal in constructed wetlands located in the tropics. Water Sci. Technol. 1997;36:1-8.

21. Lin Y-F, Jing S-R, Wang T-W, Lee D-Y. Effects of macrophytes and external carbon sources on nitrate removal from groundwater in constructed wetlands. Environ. Pollut. 2002;119: 413-420.

22. Owen DM, Amy GL, Chowdhury ZK. Characterization of natural organic matter and its relationship to treatability. AWWAR; 1993.

23. Chon K, Park J, Cho J. Humification of effluent organic matters through a surface-flow constructed wetland. Water Sci. Technol. 2013;68:1785-1794.

24. Weber WJ, Huang Q. Inclusion of persistent organic pollutants in humification processes: Direct chemical incorporation of phenanthrene via oxidative coupling. Environ. Sci. Technol. 2003;37:4221-4227.

25. Jackson TA. Humic matter in natural waters and sediments. Soil Sci. 1975;119:56-64.

26. Steinberg C, Muenster U. Geochemistry and ecological role of humic substances in lakewater. In: Aiken GR, McKnight DM, Wershaw RL, MacCarthy P, eds. Humic substances in soil, sediment, and water: Geochemistry, isolation, and characterization. New York: John Wiley \& Sons; 1985. p. 105-145.

27. Harvey GR, Henry DB. The geochemistry of humic substance in seawater. Wiley; 1985.

28. Kim S, Kaplan LA, Hatcher PG. Biodegradable dissolved organic matter in a temperate and a tropical stream determined from ultra-high resolution mass spectrometry. Limnol. Oceanogr. 2006;51:1054-1063.

29. Meyer JL, Edwards RT, Risley R. Bacterial growth on dissolved organic carbon from a blackwater river. Microb. Ecol. 1987;13:13-29.

30. Amon RM, Benner R. Rapid cycling of high-molecular-weight dissolved organic matter in the ocean. Nature 1994;369:549552.

31. Tranvik LJ, Jørgensen NO. Colloidal and dissolved organic matter in lake water: Carbohydrate and amino acid composition, and ability to support bacterial growth. Biogeochemistry 1995;30:77-97.

32. Tan KH. Humic matter in soil and the environment: Principles and controversies. CRC Press; 2014. 